\title{
Effects of Biological Control Agents on Nuisance Cyanobacterial and Diatom Blooms in Freshwater Systems
}

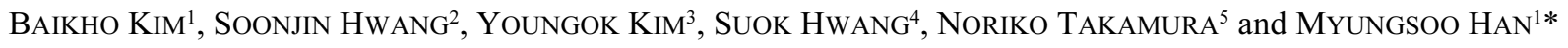 \\ ${ }^{1}$ Department of Life Science, Hanyang University, Seoul 133-791, Republic of Korea \\ 2 Department of Environmental Science, Konkuk University, Seoul 143-701, Republic of Korea \\ ${ }^{3}$ South Sea Institute, Korea Ocean Research and Development Institute, Geoje 656-830, Republic of Korea \\ ${ }^{4}$ Paldang Office, Korea Water Resource Corporation, Kyunggi 465-130, Republic of Korea \\ ${ }^{5}$ National Institute for Environmental Studies, Tsukuba 305-8506, Japan
}

(Received September 25, 2006-Accepted December 12, 2006)

Biological control agents such as bacteria and ciliates were tested alone and in combination for their abilities to decrease densities of the warm-weather cyanobacterium, Microcystis aeruginosa, and the cold-weather centric diatom, Stephanodiscus hantzschii. The growth of Microcystis aeruginosa was effectively suppressed by the algicidal bacterium, Streptomyces neyagawensis, and the predator heterotrich ciliate, Stentor roeselii. However, co-treatment increased the algal density rather than decreasing it, suggesting that Streptomyces neyagawensis and Stentor roeselii have an antagonistic relationship. Additional experiments revealed that the density of Stephanodiscus hantzschii was effectively reduced by the bacterium, Pseudomonas putida, and by the abovementioned strain of Stentor roeselii. Co-treatment had a greater antialgal effect than treatment with either bio-agent alone, indicating that the two act synergistically. These results suggest the potential antialgal efficacy of treatments with multiple biological control agents, providing new insight that may be useful for the bioremediation of nuisance algal blooms in freshwater.

Key words: algicidal bacteria, ciliate, cyanobacteria Microcystis, diatom Stephanodiscus

There have been many attempts to control nuisance algal blooms through the direct application of chemicals such as cupric-sulfate, smazine, dichromate, ozone and Llysine ${ }^{8,15,21)}$. However, these agents can cause irreversible damage to aquatic ecosystems by killing off beneficial plankton and fish ${ }^{17,18)}$. Thus, researchers are currently seeking to develop environmentally friendly bio-agents for controlling algal density, in a manner consistent with current pan-ecological and environmental approaches to lake water conservation $^{1,3,7,12)}$.

Microorganisms such as viruses, bacteria, fungi, and amoebae have been shown to kill cyanobacteria ${ }^{20,22)}$. Among these, antagonistic bacteria are potentially useful agents for algal control, as they are simple to culture and manipulate ${ }^{16,20)}$. We have previously investigated a number

\footnotetext{
* Corresponding author. E-mail address: hanms@hanyang.ac.kr; Tel.: +82-2-2220-0956; Fax: +82-2-2296-1741.
}

of aquatic bacteria, zooplanktons, and ciliates for their abilities to control algal blooms in Korea ${ }^{10,11)}$. Here, we sought to identify bio-agents capable of managing two target algae: the cyanobacterium Microcystis and the diatom Stephanodiscus. In the Pal'tang Riverine of Korea, Microcystis is often found during the warm season (water temperatures above $\left.20^{\circ} \mathrm{C}\right)^{10)}$, while Stephanodiscus is more common during the cold season (water temperatures below $\left.20^{\circ} \mathrm{C}\right)^{11)}$. Together, these two organisms are representative of many naturally occurring algal blooms.

Several previous reports have identified algicidal bacteria capable of killing cyanobacteria such as Microcystis aeruginos $a^{13,22)}$, but there have been few previous reports of bio-agents capable of managing the diatom Stephanodiscus hantzschii ${ }^{9}$. Here, we investigated the ability of several bacterial and ciliate bio-agents, alone and in combination, to decrease the density of these two representative algae. This is the first investigation of combined treatment with both 
bacteria and ciliates to control cyanobacterial and diatomal blooms in situ, and our findings provide the first evidence that the ciliate, Stentor roeselii, is algicidal to both Microcystis and Stephanodiscus.

\section{Materials and Methods}

\section{Algal culture}

The cyanobacterium, Microcystis aeruginosa NIES-44, was obtained from the National Institute for Environmental Studies, Tsukuba, Japan and cultured in CB medium (http:// www.nies.go.jp/biology/mcc/strainlist_j.htm) at $27 \pm 2{ }^{\circ} \mathrm{C}$, with shaking at $120 \mathrm{rpm}$, and a light-dark cycle of $12: 12 \mathrm{~h}$ and light intensity of $40 \mu \mathrm{mol}$ photons $\mathrm{m}^{-2} \mathrm{~s}^{-1}$. The small centric diatom, Stephanodiscus hantzschii UTCC 269, was obtained from the University of Toronto Culture Collection of Algae and Cyanobacteria (UTCC, Toronto, ON, Canada) and cultured in $\mathrm{DM}$ medium ${ }^{2)}$ at $20 \pm 2^{\circ} \mathrm{C}$ with a $12 \mathrm{~L}: 12 \mathrm{D}$ photo-cycle and $50 \mu \mathrm{mol}$ photons $\mathrm{m}^{-2} \mathrm{~s}^{-1}$. Algal cells in the exponential stage were used in all experiments, and determined by direct counting of cells using a Sedgwick-Rafter chamber under a light microscope (Nikon, Tokyo, Japan).

\section{Algicidal bacteria culture}

The bacterium Streptomyces neyagawensis HYJ0209MK50, previously reported by Choi et al. ${ }^{19)}$, was isolated using the plaque method or a soft-agar overlayer technique. In brief, algal lawns were prepared in Petri dishes containing axenic cultures of Microcystis aeruginosa NIES-44 on nutrient broth (NB) medium. These were inoculated with 1 $\mathrm{ml}$ of stream water filtered through a Nucleopore membrane (Millipore). Cultures were incubated at $25^{\circ} \mathrm{C}$ with a 12L:12D photo-cycle and 40-50 $\mu \mathrm{mol}$ photons $\mathrm{m}^{-2} \mathrm{~s}^{-1}$ for 6-8 days. Potential antialgal or algicidal bacteria were picked from clear zones where the Microcystis aeruginosa cells had lysed. These bacteria were purified, isolated, grown to the logarithmic growth phase, and inoculated into an axenic culture of Microcystis aeruginosa in NB. This gram-negative bacterium grows at $35-45^{\circ} \mathrm{C}, \mathrm{pH} 6-8$; optimal growth occurs at $40^{\circ} \mathrm{C}, \mathrm{pH} 7$. The isolates were axenically maintained under optimal growth conditions on nutrient agar (NA) plates, cryopreserved at $-76^{\circ} \mathrm{C}$ in NB medium containing $20 \%$ glycerol. The bacterial biomass of Streptomyces neyagawensis was determined by dry weight, measured as the weight difference of membrane filters (0.2$\mu \mathrm{m}$ pore size, 25-mm diameter; Whatman) before and after cultivation with the target alga. The dry weight contribution of Microcystis was ignored because it was approximately 1000-fold smaller than that of Streptomyces neyagawensis.
Pseudomonas putida HYK0203-SK02, which is capable of inhibiting the growth of Stephanodiscus hantzschii, was isolated by Kang et al. ${ }^{9)}$ using the above method, except that the algal lawns were prepared with an axenic culture of Stephanodiscus hantzschii UTCC 267 on NB. This strain of Pseudomonas putida grows at $20-30^{\circ} \mathrm{C}$ and $\mathrm{pH}$ 5-9; optimal growth occurs at $30^{\circ} \mathrm{C}$ and $\mathrm{pH} 7$. The bacterium was maintained in the dark on NA plates containing $1.5 \%$ agar, at $30^{\circ} \mathrm{C}$ and $\mathrm{pH} 7$, or cryopreserved at $-76^{\circ} \mathrm{C}$ in NB containing $20 \%$ glycerol. For enumeration of bacteria, water samples were fixed with formalin $(2 \% \mathrm{v} / \mathrm{v}$ final concentration) immediately after sampling, stained with 4',6-diamidino-2phenylindole (DAPI, $1 \mathrm{mg} \mathrm{ml}^{-1}$ ), filtered through isopore membrane filters $(0.2 \mu \mathrm{m}$, Millipore, Ireland) and counted at $1000 \mathrm{x}$ magnification using an epifluorescence microscope (Nikon, Tokyo, Japan).

\section{Antialgal ciliate culture}

For the isolation of the heterotrich ciliate, Stentor roeselii, the waterway was screened with a plankton net (pore size $40 \mu \mathrm{m}$ ) near the marginal portion of the waterway, where aquatic plants flourished. In the laboratory, the plankton samples were size fractionated with a net $(0.1-4$ $\mathrm{mm}$ ) and Stentor cells were directly picked under an inverted microscope. These cells were concentrated in a depression glass, rinsed three times with filtered water, and inoculated into a multi-well chamber containing different prey species and mixtures thereof. Samples were maintained at $23^{\circ} \mathrm{C}$, with a $12 \mathrm{~L}: 12 \mathrm{D}$ photo-cycle and $2 \mu \mathrm{mol}$ photons $\mathrm{m}^{-2} \mathrm{~s}^{-1}$. To investigate changes in ciliate density in the presence of algal prey, subsamples were fixed immediately with Bouin's solution ( $3 \% \mathrm{v} / \mathrm{v}$ final concentration), filtered with a cellulose nitrate membrane filter $(0.45 \mu \mathrm{m}$; Sartorius, Germany) and stained with protargol stain. The ciliates were enumerated using a Sedgwick-Rafter chamber under a light microscope (Nikon, Tokyo, Japan).

\section{Algicidal activity test with different agents}

Cultured M. aeruginosa maintained in CB medium (http:// www.nies.go.jp/biology/mcc/strainlist_j.htm) was diluted to $2-6 \times 10^{6}$ cells $/ \mathrm{ml}$ with the same medium, and $95-\mathrm{ml}$ aliquots were inoculated into duplicate 250-ml Erlenmeyer flasks. To investigate the antialgal effects of the Microcystis-lysing bacterium, Streptomyces neyagawensis, the bacterium was incubated in liquid NB medium at $37^{\circ} \mathrm{C}$ for $48 \mathrm{~h}$. When cell density reached $1-2 \times 10^{8}$ cells $/ \mathrm{ml}$, the culture was centrifuged at $14,000 \mathrm{~g}$ for 20 minutes, and the pellet was washed twice with sterilized NB medium. Five-milliliter $(5 \% \mathrm{v} / \mathrm{v})$ aliquots were inoculated into the algal cultures at a final 
concentration of $1-2 \times 10^{4}$ cells $/ \mathrm{ml}$. Duplicate control cultures were prepared by adding $5 \mathrm{ml}$ of NB medium to $95 \mathrm{ml}$ of Microcystis culture. The flasks were incubated at $27 \pm 2{ }^{\circ} \mathrm{C}$ with a 12L:12D photo-cycle and 40-50 $\mu \mathrm{mol}$ photons $\mathrm{m}^{-2} \mathrm{~s}^{-1}$.

To first test the antialgal effect of the Stephanodiscuslysing bacterium, Pseudomonas putida, we grew the bacterium to the logarithmic growth phase and diluted the samples with CB medium to $1.5 \times 10^{3}$ cells $/ \mathrm{ml}$ or approximately $10^{5}$ cells $/ \mathrm{ml}$. We inoculated $10 \mathrm{ml}$ of exponentially growing Stephanodiscus cells into $90 \mathrm{ml}$ of the bacterial culture, for a final algal concentration of $1 \%$. The samples were incubated as described above. Bacteria-free cultures served as the controls.

To investigate the algicidal effect of each of these organisms on Stephanodiscus, we used the same methods described above for the Microcystis assays, except that the culture flasks were incubated at $20^{\circ} \mathrm{C}$ with a $12 \mathrm{~L}: 12 \mathrm{D}$ photo-cycle and 40-50 $\mu$ mol photons $\mathrm{m}^{-2} \mathrm{~s}^{-1}$. The initial concentration of the diatom $\left(1.5 \times 10^{3}\right.$ cells $\left./ \mathrm{ml}\right)$ was similar to that encountered in nature during the bloom period. Algal cells were enumerated daily under light microscopy, as described above.

To examine the removal activity of the ciliate, Stentor rosella, on Microcystis and/or Stephanodiscus, six-well plates (Falcon, USA) were loaded with 5 cells $/ \mathrm{ml}$ of threeday starved ciliates in $5 \mathrm{ml}$ of filtered water/well. The algal concentration was $2 \times 10^{6}$ cells $/ \mathrm{ml}$ for Microcystis and/or $1.5 \times 10^{3}$ cells $/ \mathrm{ml}$ for Stephanodiscus. Algal densities and ciliate numbers were calculated daily under the light microscope after fixation with a glutaraldehyde solution.

To examine the combined algicidal effects of the tested organisms on algal growth, pairs of bio-agents (bacteria or ciliates) were introduced into culture flasks containing Microcystis and/or Stephanodiscus. The initial concentrations of bacteria and starved ciliates, and the final culture volumes were very similar to those described above. $\mathrm{Cul}-$ tures were maintained at $20^{\circ} \mathrm{C}$, with a $12 \mathrm{~L}: 12 \mathrm{D}$ photo-cycle and light intensity of $2 \mu \mathrm{mol}$ photons $\mathrm{m}^{-2} \mathrm{~s}^{-1}$. Ciliates and algae were counted using a Sedgwick-Rafter chamber under an inverted microscope (Nikon, Tokyo, Japan).

To further investigate the competitive relationship between the bacterium and the ciliate, the bio-agents were co-cultured in filtered freshwater under the same conditions. As the bacteria grew similarly under dark conditions and 2 $\mu \mathrm{mol}$ photons $\mathrm{m}^{-2} \mathrm{~s}^{-1}$, we were able to ignore the influences of light in our calculations. Cell densities of Streptomyces, Pseudomonas and Stentor populations were measured or enumerated daily for 6-7 days.

\section{Data analysis}

The algicidal activity (AA) of the bacteria or ciliate on Microcystis aeruginosa and Sephanodiscus hantzschii was calculated using the formula $\mathrm{AA}=(1-\mathrm{D} / \mathrm{Do}) \times 100$, where Do and D are the cell densities in the control and treated groups, respectively, at the end of each experiment. The AA increase (indicating an effective algicide) or decrease (indicating an ineffective algicide) of target algae Microcystis aeruginosa and Stephanodiscus hantzschii in the presence of biological control agents was analyzed by the Student's $t$ test.

\section{Results}

The bacterium Streptomyces neyagawensis effectively suppressed the growth of Microcystis aeruginosa cultured in filtered water, without any apparent change in the biomass of Streptomyces neyagawensis (Fig. 1 upper). The lack of change in the bacterial biomass may be attributed to

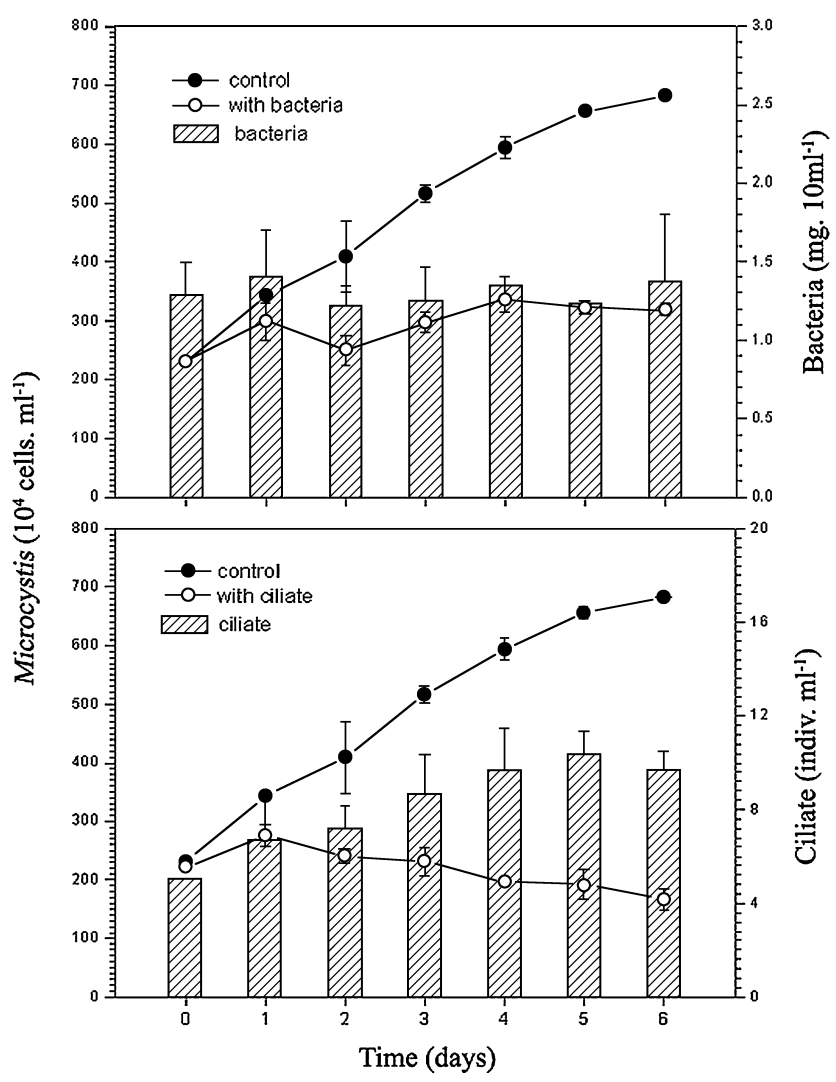

Fig. 1. Antialgal effect of the bacterium Streptomyces nagayawensis (upper) and the ciliate Stentor roeselii (lower) on the cyanobacterium Microcystis aeruginosa in filtered water. 


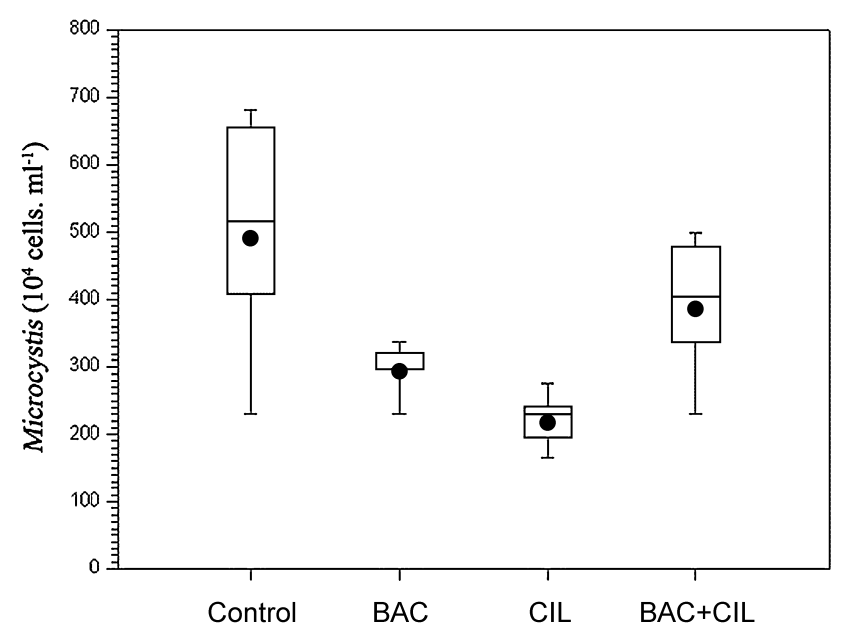

Fig. 2. Comparison of single and combined antialgal effects of the bacterium Streptomyces nagayawensis and the ciliate Stentor roeselii on the cyanobacterium Microcystis aeruginosa in filtered water. The heights of the blank boxes represent the growth of $M$. aeruginosa and its inhibition or stimulation by the treatments. $\mathrm{BAC}+\mathrm{CIL}$, co-treatment with bacteria (BAC) and ciliates (CIL).

the differences in optimal temperature and $\mathrm{pH}$ ranges between the bacteria and the algae. The ciliate, Stentor roeselii, gradually inhibited the growth of Microcystis cultured in filtered water beginning one day after cultivation, while its abundance increased slightly over the first five days of cultivation, and declined thereafter (Fig. 1 lower). Unexpectedly, combined treatment with bacteria and ciliates did not effectively inhibit the growth of Microcystis (Fig. 2), suggesting possible competition between the bacteria and ciliates. However, the cell densities and growth of Microcystis aeruginosa in the combined treatment cultures were lower than those in control cultures. In mixed bacterial/ciliate cultures without nutrient supplementation, the growth of the ciliate was severely limited (decreased to $80 \%$ of the control) on the first day, with less than $100 \%$ mortality by the second day (Fig. 3).

The bacterium Pseudomonas putida effectively inhibited the growth of the diatom Stephanodiscus hantzschii in filtered water, decreasing its population to $80 \%$ of control levels (Fig. 4 upper). The bacterial population gradually decreased with time, and the density of the diatom declined to about $14 \%$ of the control level after eight days of cultivation. The ciliate Stentor roeselii similarly inhibited growth of Stephanodiscus hantzschii, although its effect was weaker than that of Pseudomonas putida (Fig. 4 lower), and all ciliates died within four days of cultivation. In contrast to our finding of decreased anti-algal effects following cotreatment of Microcystis, the treatment of Stephanodiscus

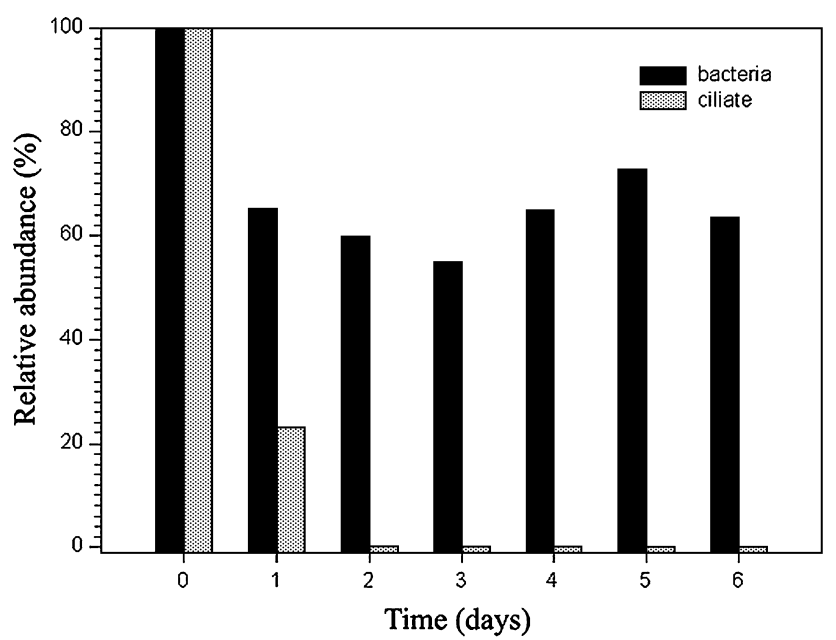

Fig. 3. Changes in the relative abundances of ciliate (Stentor roeselii) and bacteria (Streptomyces nagayawensis) in mixed cultures.

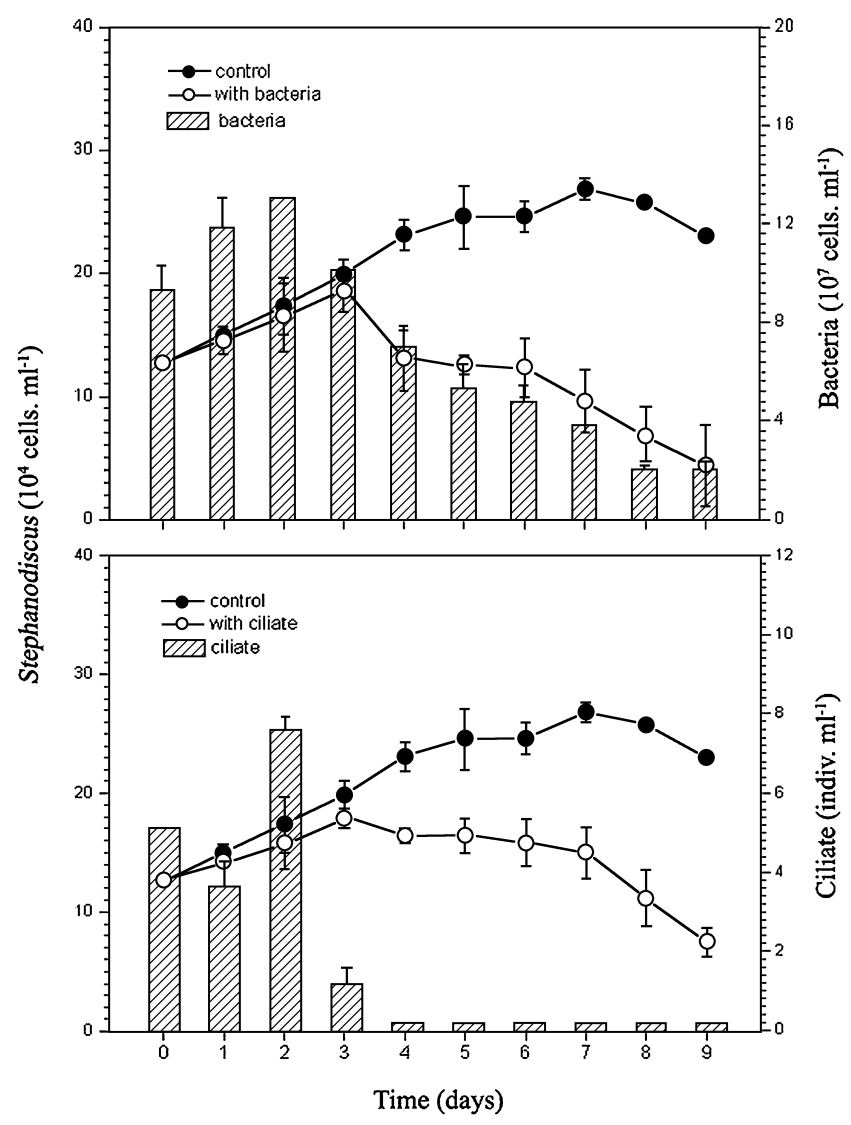

Fig. 4. Antialgal effect of Pseudomonas putida (upper) and the ciliate Stentor roeselii (lower) on the diatom Stephanodiscus hantzschii in filtered water.

hantzschii with Pseudomonas putida plus Stentor roeselii was more effective than either of the single treatments alone 


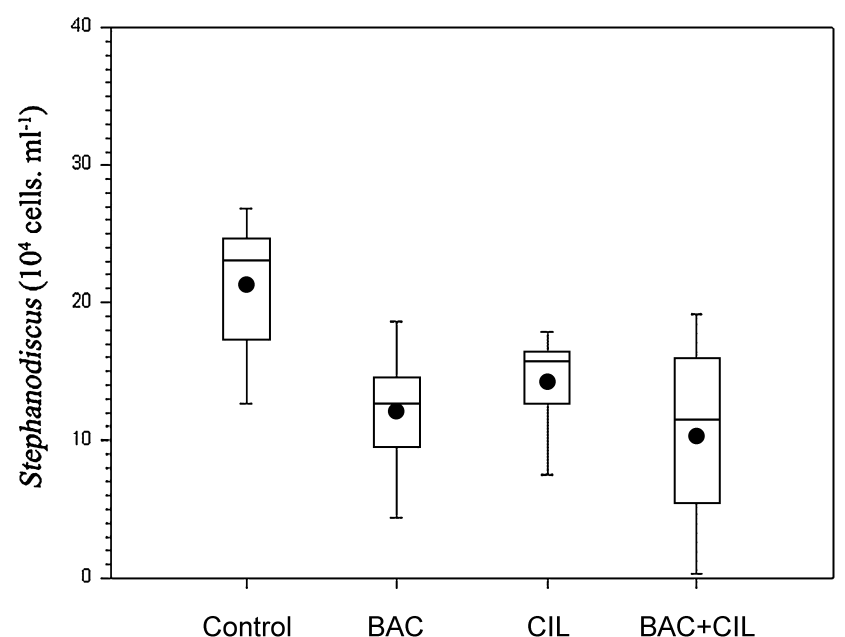

Fig. 5. Comparison of single and combined antialgal effects of the bacterium Pseudomonas putida, the ciliate Stentor roeselii, and combined treatments on the diatom Stephanodiscus hantzschii in filtered water. The heights of the blank boxes represent the growth of $S$. hantzschii and its inhibition or stimulation by each treatment. $\mathrm{BAC}+\mathrm{CIL}$, co-treatment with bacteria (BAC) plus ciliates (CIL).

(Fig. 5). Following the combined treatment, Stephanodiscus. hantzschii levels reached zero within nine days of cultivation.

The treatment of Stephanodiscus hantzschii with Pseudomonas putida plus Stentor roeselii decreased the algal cell density, whereas treatment of $M$. aeruginosa with the bacterium Streptomyces neyagawensis plus the ciliate did not effectively inhibit algal growth (Table 1).

\section{Discussion}

Our results clearly show that the efficacies of bio-agents alone and combination vary depending on the target algae and the agents themselves. In the presence of the Micro- cystis-lysing bacterium, Streptomyces neyagawensis ${ }^{4)}$, the density of Microcystis fluctuated near the average value, whereas control cultures lacking the lytic bacterium showed a steady increase in Microcystis cell density $(\mathrm{AA}=0.05)$, indicating that the bacterium had a suppressive effect on the proliferation of Microcystis. In the presence of the Stephanodiscus-lysing bacterium, Pseudomonas putida ${ }^{9}$, the cell density of the diatom Stephanodiscus hantzschii gradually decreased over time $(\mathrm{AA}=-0.12)$. In terms of bacterial growth patterns, the density of Streptomyces neyagawensis fluctuated near the initial density in the presence of Microcystis aeruginosa, while the density of Pseudomonas putida increased during the first two days of diatom culture and decreased sharply thereafter. Our observation of feeble or nonexistent bacterial growth in the presence of algae is perhaps due to differences between the conditions optimal for algal growth used in our experiments and those preferred by the bacteria. The growth of Microcystis and Stephanodiscus in the presence of the ciliate, Stentor roeselii, showed a similar pattern to that observed in the presence of the two bacteria. However, during the co-treatments, the ciliate showed different growth patterns depending on the bacteria; the Stentor cell density declined to zero after four days of cultivation with Stephanodiscus hantzschii, whereas the ciliate levels gradually increased in the presence of Microcystis aeruginosa.

Surprisingly, we found that the co-treatment of Microcystis-containing cultures with Streptomyces neyagawensis and Stentor roeselii had a smaller algicidal effect than treatment with either agent alone, perhaps due to some sort of antagonistic effect. Our results regarding growth patterns (Fig. 5) showed that Streptomyces neyagawensis and ciliates grown in nutrient-free filtered water of the sampling stations decreased in number simultaneously; however, this observation was insufficient to explain all of the observed differences. In the presence of Streptomyces neyagawensis, ciliate

Table 1. Decreases in Microcystis aeruginosa and Stephanodiscus hantzschii biomass following individual or combined treatment with bacteria and ciliates, and their algicidal activities (AA) on both algae

\begin{tabular}{clrl}
\hline Target algae & \multicolumn{1}{c}{ Treatments } & AA & \multicolumn{1}{c}{$\mathrm{r}$} \\
\hline Microcystis aeruginosa & Streptomyces nagayawensis SM02 & 0.05 & $0.97^{* *}$ \\
& Stentor roeselii & -0.04 & $0.85^{*}$ \\
& Streptomyces + Stentor & 0.10 & $0.92^{* *}$ \\
Stephanodiscus hantzschii & Pseudomonas putida SK02 & -0.12 & $0.97^{* * *}$ \\
& Stentor roeselii & -0.06 & $0.98^{* * *}$ \\
& Pseudomonas + Stentor & -0.42 & $0.96^{* * *}$ \\
\hline
\end{tabular}

* $\mathrm{P}<0.05, * * \mathrm{P}<0.01, * * * \mathrm{P}<0.001$ 
levels decreased more severely than did Streptomyces neyagawensis levels, with total ciliate mortality occurring within four days of cultivation. This phenomenon might suggest that the bacterium may even have an anti-ciliate property, similar to the anti-nematodal and antibiotic properties seen in other bacteria ${ }^{5,6)}$. Further study will be required to determine the relationship between co-applied bio-agents in an aquatic ecosystem.

We also investigated the effect of a second bacterium, Pseudomonas putida, and the ciliate, Stentor roeselii, on the diatom, Stephanodiscus. We observed widespread ciliate death in the presence of Stephanodiscus, possibly due to a lack of nutrients. We used the same nutrient conditions as found in the lake, and seeded cultures with less than $10^{5}$ diatoms $/ \mathrm{ml}$, which is consistent with the diatom load found in nature. The Micorcystis aeruginosa NIES-44 used in this study is not a toxic strain and does not produce microcystin, in contrast to the previously reported Micorcystis aeruginosa NIES-298 ${ }^{23}$. Although the target algae were inhibited by treatment with these bio-agents, the co-culture conditions did not seem to be optimal for growth of the bacteria and/or ciliate. However, our results revealed that co-treatment of Stephanodiscus with Pseudomonas putida and Stentor roeselii more effectively inhibited the diatom than did treatment with each agent alone, suggesting some kind of synergistic interaction.

Collectively, these results indicate that the efficacies of bio-agents alone and in combination vary depending on the target algae and the agents themselves. More work will be required to investigate the use of bio-agents such as algicidal bacteria and ciliates to control cyanobacterial and diatomaceous blooms. A better understanding of the interactions among bio-agents will allow researchers to select relevant predators and/or bacteria within each freshwater ecosystem. Here, our preliminary data show the possibility of synergistic and antagonistic effects of bio-agents during co-treatments, providing new insight that may be useful for the future bioremediation of diatomaceous and cyanobacterial blooms.

\section{Acknowledgements}

This work was supported by the Korea Research Foundation Grant (KRF-2004-C00018). The authors are grateful to two anonymous reviewers for valuable comments on the original manuscript. We deeply thank four individuals, M.H. Park, Y.H. Kang, H.J. Choi, and S.K. Ka, for their technical assistance.

\section{References}

1) Barnet, Y.M., M.J. Daft and W.D. Stewart. 1981. Cyanobacteriacyanophage interactions in continuous culture. J. Bacteriol. 51: 541-552.

2) Beakes, G., H.M. Canter and G.H.M. Jaworski. 1988. Zoospores ultrastructure of Zygorhizidium affluens Canter and Z. planktonicum Canter, two chytrids parasitizing the diatom Asterionella formosa Hassall. Can. J. Bot. 66: 1054-1067.

3) Brabrand, A., B.A. Faafeng, T. Kallquist and J.P. Nilssen. 1983. Biological control of undesirable cyanobacteria in culturally eutrophic lakes. Oecologia 60: 1-5.

4) Choi, H.J., B.H. Kim, J.D. Kim and M.S. Han. 2005. Streptomyces neyagawaensis as a control for the harzardous biomass of Microcystis aeruginosa (Cyanobacteria) in eutrophic freshwaters. Biol. Control 33: 335-343.

5) Dicklw, M.B., N. Acosta and B.M. Zuckerman. 1993. A novel Streptomyces species for controlling plant-parastic nematodes. J. Chem. Ecol. 19: 159-173.

6) Esnard, J., T.L. Potter and B.M. Zuckerman. 1995. Streptomyces costarinus sp. nov., isolated from nematode-supressive soil. Int. J. Syst. Bacteriol. 45: 775-779.

7) Imai, I., Y. Ishida and Y. Hata. 1993. Killing of marine phytoplankton by a gliding bacterium Cytophaga sp., isolated from the coastal sea of Japan. Mar. Biol. 116: 527-532.

8) Jeffries, M. and D. Mills. 1990. Freshwater ecology-Principles and applications. Belhavan Press, London, UK.

9) Kang, Y.H., J.D. Kim, B.H. Kim, D.S. Kong and M.S. Han. 2005. Isolation and characterization of a bio-agent antagonistic to diatom, Stephanodiscus hantzschii. J. Appl. Microbiol. 98: 1030-1038.

10) Kim, B.H., H.J. Choi and M.S. Han. 2003. Potential in the application for biological control of harmful algal bloom cause by Microcystis aeruginosa. Kor. J. Limnol. 36: 64-69.

11) Kim, B.H., Y.H. Kang and M.S. Han. 2004. Potential in the application for biological control of winter diatom bloom caused by Stephanodiscus hantzschii. Kor. J. Limnol. 37: 236-240.

12) Manage, P.M., Z. Kawabata and S. Nakano. 2000. Algicidal effect of the bacterium Alcaligenes denitrificans on Microcystis spp. Aquat. Microb. Ecol. 22: 111-117.

13) Manage, P.M., S. Kawabata and S.S. Nakano. 2001. Dynamics of cyanophage-like and algicidal bacteria causing Microcystis aeruginosa mortality. Limnology 2: 73-78.

14) McGuire, R.M., J.M. Jones, E.G. Means, G. Lzaquive and A.E. Reston. 1984. Controlling attached blue-green algae with copper sulfate. Research Technol. 27: 60-65.

15) Rashidan, K.K. and D.F. Bird. 2001. Role of predatory bacteria in the termination of a cyanobacterial bloom. Microb. Ecol. 41: 97105.

16) Redhead, K. and S.J. Wright. 1978. Isolation and properties of fungi that lyse blue-green algae. Appl. Environ. Microbiol. 35: 962-969.

17) Reynolds, C.S. 1984. The ecology of freshwater phytoplankton. Cambridge University press. Cambridge.

18) Reyssac, S.J. and M. Pletikosic. 1990. Cyanobacteria in fishponds. Aquaculture 88: 1-20.

19) Safferman, R.S. and M.E. Morris. 1962. Evaluation of natural products for algicidal properties. J. Appl. Microbiol. 10: 289292.

20) Sigee, D.C., R. Glenn, M.J. Andrews, E.G. Bellinger, R.D. 
Butler, H.A.S. Epton and R.D. Hendry. 1999. Biological control of cyanobacteria: principles and possibilities. Hydrobiologia 395/ 396: $161-172$.

21) Takamura, Y., T. Yamada, A. Kimoto, N. Kanehama, T. Tanaka, S. Nakadaira and O. Yagi. 2004. Growth inhibition of microcystis cyanobacteria by L-lysine and disappearance of natural microcystis blooms with spraying. Microbes Environ. 19: 31-39

22) Yamamoto, Y., T. Kouchiwa, Y. Hodoki, K. Hotta, H. Uchida and K. Harada. 1998. Distribution and identification of actinomycetes lysing cyanobacteria in a eutrophic lake. J. Appl. Phycol. 10: 391-397.

23) Yasuno, M., Y. Sugaya, K. Kaya and M.M. Watanabe. 2000. Variations in the toxicity of Microcystis species to Moina macrocopa. In Watanabe M.M. and Kaya K. (eds.). Advances in microalgal and protozoal studies in Asia. Global Environmental Forum. pp. 43-51. 